1 identity attitudes 28(3), 250-257.

) self-actualization $y, 32(3), 431-440$. $c$ and background 7-24.

or use with diverse

American adoles-

Identity Attitude

and recommendantity development: , \& Henry. ipproach to racial lett (Ed.), Forging (pp. 23-56). West

M. (1997). Multiof reliability and 05-815.

sus, T. M. (1998). African American

: interactive nature zation (pp. 47-69).

;chool adjustment: $36(1), 21-30$.

'ross' stage model ice. In R. L. Jones rvention (pp. 121-

ies among African ademic Press.
ISSN: $1529-8868$ print $1529-8876$ online

DOI: $10.1080 / 15298860390232868$
$\Psi$ Psychology Press

Taylor \& Francis Group

\title{
Gendered Racial Identity and Involvement with School
}

\author{
DAPHNA OYSERMAN
}

University of Michigan, Ann Arbor, Michigan, USA

DEBORAH BYBEE

Michigan State University, Ann Arbor, Michigan, USA

\section{KATHY TERRY}

University of Michigan, Ann Arbor, Michigan, USA
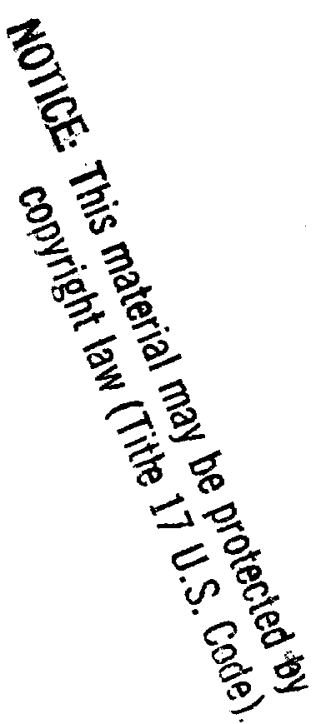

\begin{abstract}
We studied the influence of three components of racial-ethnic identity ( $R E I)$ on school involvement (including possible selves) in middle school with an AfricanAmerican, low-income, urban sample. We explored the impact of one REI component, "awareness of racism," and we hypothesized that the nature of the effect of the other two components-positive ingroup "connectedness" and "embedded achievement"-would differ by gender because they offset gender differences in agency and relatedness. We developed a measure of $R E I$ (pilot $N=139$ ) and examined change in involvement over the eighth-grade year (study $N=101$ ) using hierarchical regression. For boys, the "connectedness" component of REI predicted improved grades, increased study time, better attendance, and more numerous strategies to attain academic possible selves; for girls, the "embedded achievement" component of REI predicted improvement in grades. Youth high in all three elements of REI became more concerned about school.
\end{abstract}

\section{Gendered Racial Identity, Possible Selves, and Involvement with Schools}

Change, shift, and uncertainty are hallmarks of early adolescence. Puberty carries with it gendered changes, both in what one looks like and in social demands, expectations and responses (Elliott \& Feldman, 1990; Leffert \& Petersen, 1995). In light of these changes, adolescents must re-assess who they are now and who they plausibly could become (Banaji \& Prentice, 1994; Cantor \& Zirkel, 1990; Harter \& Marold, 1991; Kihlstrom \& Klein, 1994). Since knowing the future is impossible, adolescents must seek clues to their future identity from the behavior and

Received 25 May 2003; accepted 5 June 2003.

We thank the middle school students who participated in the studies and Monique Clinton for assistance in coding. Partial funding for data collection came from a W.T. Grant Faculty Scholars award and from the Michigan Prevention Research Center, NIMH Grant \#P50MH38330 (Richard Price and Amiram Vinokur, PIs) to Oyserman. The first author gratefully acknowledges the support of the Center for Advanced Studies in the Behavioral Sciences and the W.T. Grant Foundation during the writing phase.

Address correspondence to Daphna Oyserman, Institute for Social Research, University of Michigan, 426 Thompson, Ann Arbor MI 48109-1248. E-mail: daphna.oyserman@umich.edu 
attainments of similar others as well as from their own current behaviors and skills

Current activities become self-symbolizing opportunities or concrete markers that one can become the self one wants to be, and that one is moving toward cherished, and away from feared, possible selves (Oyserman \& Markus, 1993).

In much the same way that current activities help youth scaffold future selves, social identities such as gender identity and racial-ethnic identity (REI) can become a nexus for self-definition. REI and gender identities focus attention on those to whom one is similar and what is expected, valued, and normative for members of one's gender and racial-ethnic groups-how members act, what they value, and therefore what the self can become. Indeed, there is some evidence that racial identification becomes more central to self-definition in adolescence than it was before and will be later (Quintana, 1998). Of particular interest to us are the ways racial identities intertwine to influence possible selves and behavioral intentions focused on school.

\section{School as a Contested Domain of Self-Definition}

Social class, race, and gender are associated with teacher and student expectations for school involvement (see Kowaleski-Jones \& Duncan, 1999; Madon, Jussim, \& off-track, leading fegative expectations from in-or outgroup others can bump students Stangor, \& Milne to lower school performance (Stangor \& Lange, 1994; Macrae, stereotype both by 1994). African-American teens may reinforce a negative ingroup threatening to one's connetic academic successes and achievements as "not Black" and taunting or isolating Black peen the Black community (e.g., Ogbu, 1991) and by ficiently "Black"(Dyson, 1993; Fordham \& have a similar effect.

The current research focuses on gender-specific ways that REI can promote involvement with school in a high-poverty setting. We ways that REI can promote positive impact of REI in high-poverty settings We chose to focus on the potential socioeconomic status and minority group me combination of low vement with school. We propose group membership increases risk of low involnegative messages about the likelihe that REI can provide a needed buffer against REI can buffer youth by organihood of success for poor and minority youth. First, ence, regulating affect and channeling their understanding of their academic experi(Oyserman \& Markus, 1993. Oyserma motivation to persist and engage in school motivation to stay involved in school by Packer, 1996). Second, REI can bolster the ingroup and a positive valuation by providing a positive sense of connection to important ingroup others. Further, as detaied in the achievement through the eyes of gendered, because gender socialization experion the next section, REI is likely to be

\section{A Model of REI}

Building on previous qualitative and quantitative research on the content of REI (Allen, Dawson, \& Brown, 1989; Azibo, 1991; Daniels, Wodarski, \& Davis, 1987; Jackson; 1991; Jencks, 1991; Kirschenman \& Neckerman, 1991; McAddo, 1991), we first is termed connectednef REI that are relevant to the question of academic focus. The positive sense of belonging or connection to the ingroup. Connectedness focuses on a traditions and future. Thinking and being part of or linked to the ingroup, its history, among REI researchers, a number of REI in terms of connectedness is common ethnic or racial group, also termed "postive have noted that connectedness to one's 
t behaviors and skills oncrete markers that ing toward cherished,
1993).

caffold future selves, (REI) can become in on those to whom $r$ members of one's 'alue, and therefore racial identification $s$ before and will be ys racial identities focused on school.

'dent expectations Iadon, Jussim, \& an bump students e, 1994; Macrae, negative ingroup "not Black" and u, 1991) and by white" or insufstereotypes can

I can promote on the potential ination of low of low involbuffer against y youth. First, demic experiage in school I can bolster :onnection to 1 the eyes of s likely to be foci of REI.

ent of REI 'avis, 1987; , 1991), we focus. The 'cuses on a ts history, common $s$ to one's g. Cross,
1991; Phinney, 1996). In fact, lack of connectedness, feeling unsure that one does belong and is a member of the ingroup is viewed as highly detrimental to well-being. This can be seen in the following excerpt from Lewin's discussion of the "Jewish problem," by which he meant the lack of personal well-being among Jews who experience negative stereotyping as members of a minority group while not being sure if they really fit into the ingroup either: " $[\mathrm{O}]$ ne of the greatest theoretical and practical difficulties of the Jewish problem [is] that Jewish people are often, in a great degree, uncertain of their relation to the Jewish group. They are uncertain whether they actually belong to the Jewish group, in what respect they belong to this group, and in what degree" (Lewin, 1948, p. 148). In our own research with youth, we find that the experience of being African American is commonly described in terms of feelings of positive connectedness. For example, in a sample of eighth graders, one youth wrote "to be black is wonderful, I am a member of my community," while another wrote that being African American means "acting my color and not someone else's color."

We term the second component of REI embedded achievement, or the belief that achievement is an ingroup identifier, a part of being a good ingroup member, and the related sense that achievement of one ingroup member helps others in the group to succeed (Oyserman, Gant, \& Ager, 1995). We reasoned that youth who do not actively resist negative academic stereotypes by directly addressing academic ability within REI would not be able to recruit sufficient motivational attention to override these messages and stay focused on school success. Thus, for African Americans, viewing achievement as part of being Black facilitates identification with academic goals and reduces dis-identification with school and "cultural inversion" by which school is viewed as not "African American" (e.g. Ford, 1992; Fordham, 1988). Examples of embedded achievement as a component of REI from our research with eighth-grade African American youth include statements such as "hard working in school, intelligent," "Achievement. And every black person can do everything that they want to do," as responses to open-ended questions about what it means to be African American.

We term the third component of REI awareness of racism. This component of REI focuses on a consciousness or awareness of the obstacles that members of one's ingroup may have to deal with in face-to-face interactions or simply due to the structure of society. Awareness of racism is a central part of REI (Stevenson, 1995) and is sometimes termed the "public" component of REI (Crocker, Luhtanen, Blaine, \& Broadnax, 1994). Awareness of racism supports two central self-concept tasksfeeling good about one's self and making sense of one's experience. Awareness of racism provides a non-self-denigrating explanation for failures and setbacks, and thus shields competency beliefs (e.g. Cose, 1993; Essed, 1990; Parham \& Helms, 1985) and provides predictions of how others will respond to the self. In our own research, youth commonly mention issues related to an awareness of racism when asked to describe what being African American means to them. For example, one youth wrote that being African American means "people sometimes don't believe in us-even when you are mixed, somebody always has something negative to say." Another youth wrote "that we may not be expected to do certain things or jobs," while a third wrote that being African American means "that my appearance affects what people think of me."

\section{Gendered REI}

We refer to REI as gendered for a number of reasons. First, content of racial stereotypes are gendered (Oyserman \& Harrison, 1998). Second, socialization practices are gendered, emphasizing relationality for girls and autonomy and independence 
for boys (Cross \& Madson, 1997; Stevens, 1997). Third, relationality is higher in young women than in young men (Gardner, Gabriel, \& Lee, 1999).

Typical foci of male gender socialization can be helpful in promoting boys' academic achievement but only in contexts that provide appropriate resources and opportunities to succeed. When combined with poverty and low employment prospects (Aguirre \& Turner, 1998; Bowman, 1992; Staples, 1991), autonomy socialization reduces commitment to long-term academic goals by facilitating disengagement from the conventional groups-school, community, family, and kin that focus on schooling even when the odds of success seem low (Allen, 1992; Bowman, 1992; Massey, 1991). Conversely, typical foci of female gender socialization provide a clear path of engagement with these groups by highlighting ways the self is interwoven with, connected to, and responsible for and to others (Cross \& Madson, 1997; Kashima et al., 1995; Markus \& Oyserman, 1989). Indeed, African-American girls are more likely to be embedded in maternally focused kin networks and be responsible for support and care of young children (Jackson, 1991; McNair-Knox, 1991; Miller, 1995; Wilson, 1993).

REI can provide an important counterbalance to gender socialization. In high poverty contexts with low prospects for independent advancement, the component of REI that focuses on positive connection to the ingroup provides an important counterbalance to male gender socialization for autonomy (e.g., Bowser \& Perkins, 1991; Oyserman et al., 1995). REI connectedness binds young men to conventional groups and makes their social sanctions matter, thereby providing the framework for continued focus on school. Conversely, REI embedded achievement focuses on achievement in school and career as part of one's network commitment and can provide a positive counterbalance to female gender socialization for relationality (see for example, Shorter-Gooden \& Washington, 1996). By making achievement a way of being a member of the group rather than a separated, nonconnected individual characteristic, REI embedded achievement provides a means for girls to view focus on school as congruent with interrelatedness. Moreover, embedded achievement can buffer girls from negative sanctions against personal or independent achievement; when achievement is connected with REI, it may free girls to take on this stance (Rudman, 1998). This would suggest that REI connectedness promotes school involvement for boys, not girls and that REI embedded achievement promotes school involvement for girls, not boys.

With regard to the third element of REI, awareness of racism, we operationalized the awareness of racism component of gendered REI as sensitivity to the existence of barriers or obstacles due to group membership, and awareness of outgroup devaluation. Simply being high in awareness of racism may dampen schoolfocus by causing youth to withdraw effort in a domain in which they know there are obstacles to their success (Crocker \& Major, 1989; Oyserman \& Harrison, 1998). However, when high awareness of racism is combined with feelings of connectedness and embedded achievement, it may promote persistence and involvement in school by depersonalizing failures, highlighting the need to keep trying. Thus, youth high in all three of the REI components should be more concerned about succeeding in school, whether male or female.

\section{Hypotheses}

Following our model, we hypothesized that youth would describe REI in terms of three components (awareness of racism, connectedness, and embedded achievement) 
rality is higher in ). promoting boys' ate resources and low employment 1991), autonomy $\checkmark$ facilitating disnily, and kin that , 1992; Bowman, alization provide ways the self is 'ross \& Madson, frican-American etworks and be McNair-Knox, ization. In high the component s an important vser \& Perkins, o conventional framework for int focuses on tment and can lationality (see evement a way :ted individual : to view focus hievement can achievement; on this stance motes school ent promotes

im, we opersitivity to the eness of outnpen schoollow there are rison, 1998). onnectedness snt in school 'outh high in ucceeding in

in terms of shievement) and that these REI components would interact with gender to influence school involvement and achievement. Specifically we hypothesized that: (a) REI connectedness would promote school involvement and achievement for boys, not girls; (b) REI embedded achievement would promote school involvement and achievement for girls, not boys; and (c) REI awareness of racism would promote concern with school success when combined with REI connectedness (for boys) and REI embedded achievement (for girls).

\section{Method}

\section{Overview}

Our model focused on the interplay between gender and REI in high poverty contexts, so we collected data at a high poverty school where $92 \%$ of the enrolled students received free and/or reduced lunch or came from families receiving public assistance (see Miller, 1995 for definition of "high poverty" context). We first needed to develop a closed-ended measure of REI, using data collected in the spring of the 1994-1995 school year. Using the newly developed measure, we then explored the influence of REI on school involvement in two cohorts (1995-1996 and 1997-1998) of eight graders who participated during the Fall and Spring of their eighth-grade year. To explore the influence of REI on involvement with school in this latter set of cohorts, we used Fall levels of African-American identity to predict (a) Spring academic possible selves, (b) strategies to attain these possible selves, (c) self-report of grades, (d) attendance, (e) time spent doing homework, and (f) concern about succeeding in school.

\section{Participants}

We asked all eighth graders in a high-poverty-concentration middle school to fill out a questionnaire about their thoughts and feelings. Students participated in either the scale development phase (Spring of the 1994-1995 school year) or the study phase (Fall and Spring of the 1995-1996 and 1997-1998 school years). In the scale development phase, participating eighth graders were African American $(n=139)$. In the study phase, two eighth-grade cohorts (1995-1996 and 1997-1998) participated. Data from the two non-African-American students were discarded; as were data from 31 students who participated in an after school enrichment program targeting school involvement; 132 African-American male (64) and female (68) students completed both Fall (Time 1) and Spring (Time 2) assessments during the study phase.

\section{Procedure}

The procedure followed for both Study 1 and Study 2 was as follows: Parents were mailed letters describing the survey and were asked for permission to have their child participate as part of the school's improvement efforts. Because the survey was part of school efforts, we used passive consent, and less than $5 \%$ of the parents responded that they did not want their child to participate in the survey. We provided these youths with worksheets during the in-class survey administration so that their peers would not know that their parents had refused their participation. We obtained youth assent by explaining the purpose and voluntary nature of the questionnaire. 
Two research staff (either the first and third authors, or a research assistant) remained in the classroom to read aloud instructions and portions of the ques. tionnaire and to answer questions during the study session. The classroom teacher was not in the classroom during the survey. For the two cohorts in the study phase, we administered questionnaires in October through early November and again in May through early June each year.

To obtain surveys, the third author returned to the school on multiple occasions over a two-week period to locate all still-enrolled students. Given the high mobility of students at the school, we compared youth assessed at both times with youth present for only one of the assessments on the study variables (gender, grades, study time, school attendance, REI, concern about school, and possible selves). The only significant difference was for attendance. Not surprisingly, the mobile youth attended school less when they were enrolled than did the students who stayed at the school all year (Fall only vs. all year, $F[1,180]=21.28, p<.001, M=3.19$ vs. $M=3.91$, and Spring only vs. all year $F[1,166]=9.59, \mathrm{p}<.01, M=3.23$ vs. $M=4.16$, where $3=$ "absent once every few weeks" and $4=$ "absent once a month or so").

\section{Study 1}

To determine whether REI can be described in terms of the three components, we developed a close-ended scale of REI. We began with a list of the most common words or phrases generated with our earlier interview-based, open-ended REI measure (Oyserman et al., 1995). Our goal was to ascertain whether responses that were common when freely generated would have a reasonable distribution and construct reliability when represented in closed format. To reduce the possibility of social desirability responding, we asked youth to distribute stickers on which each of the common words or phrases was printed on a sheet of paper marked "me" and "not me."

\section{Measure of REI}

Youth were given a large sheet of paper divided into two large blocks labeled "me" and "not me." The "me" block, on the right half of the page was divided into two smaller blocks labeled "describes me" and "describes me very much." Similarly, the "not me" block on the left half of the page was divided into two smaller blocks labeled "sometimes describes me" and "almost never describes me." Youth were given a plastic bag of stickers with self-descriptors printed on them. Students were to take out each sticker and placed it on the block that best fit how much it described them as an African American, discarding stickers that never described them. Discarded descriptors were coded as 0 , "hardly ever me" as 1, "sometimes me" as 2, "describes me" as 3, and "very much describes me" as 4. Example stickers for each subscale were, for Connectedness: "member of my church," "part of my neighborhood;" for Achievement: "work hard in school," "proud if I succeed in school;" and for Awareness of Racism: "stared at," "excluded."

\section{Results}

The sticker technique resulted in adequate measures of each component of REI: Connectedness ( 7 items, $M=1.82, S D=1.03, \alpha=.79$ ), Awareness of Racism 
iearch assistant) ins of the quesassroom teacher the study phase, ver and again in

ultiple occasions he high mobility mes with youth er, grades, study ielves). The only sile youth atten1o stayed at the .19 vs. $M=3.91$, $M=4.16$, where so").

components, we most common pen-ended REI iether responses ble distribution ze the possibility s on which each arked "me" and

ks labeled "me" livided into two . Similarly, the , smaller blocks e." Youth were itudents were to uch it described ibed them. Distimes me" as 2 , itickers for each of my neighborin school;" and

ponent of REI: ess of Racism
(7 items, $M=1.07, S D=.79, \alpha=.77$ ), and Embedded Achievement (8 items, $M=2.26, S D=.88, \alpha=.69$ ).

\section{Discussion}

The mean score of the REI component awareness of racism was "hardly ever describes me" the mean response to the REI components connectedness and embedded achievement was "sometimes describes me." Variability around the mean suggests that the two components of REI of most interest in studying gendered consequences are common. The sticker method provides an adequate measure of the components of REI but took a full class period to complete. Therefore in Study 2 we attempted a shorter version of REI to examine the gendered effect of REI on school involvement and achievement.

\section{Study 2}

\section{Measures}

REI was measured in the Fall with three three-item, 5-point Likert-type $(1=$ strongly disagree to $5=$ strongly agree) scales using items that had reasonable response distribution in the previous study and were congruent with scales published elsewhere (especially Phinney, 1990). Scale internal consistency, reported below, was low but adequate given the brevity of the new scale. Though response scales differed, levels of response were parallel with both techniques. Thus, in the previous study, average youth responses were in the range of "sometimes me" for Connectedness and Embedded Achievement and "hardly ever me" for Awareness of racism. In the current study, as listed below, mean responses were in the neutral range for Awareness of racism and between neutral and agree for Connectedness and Embedded Achievement. Connectedness, $M=4.07, S D=0.71, \alpha=.74$ ("I feel close to others in my community,"); Awareness of Racism, $M=3.23, S D=0.90, \alpha=.58$ ("Some people might have negative ideas about my abilities because I am Black"), Embedded Achievement, $M=3.79, S D=0.81, \alpha=.60$ ("It is important for my family and community that I succeed in school"). Reliability was similar to reliability reported in other recent studies of urban African-American adolescents (e.g., $\alpha=.69$ for an 8-item scale; Paschall \& Hubbard, 1998). Embedded Achievement and Connectedness were moderately correlated $(r=.34)$; neither was significantly correlated with Awareness of Racism $(r<.15)$.

\section{School Involvement}

Six dimensions of school involvement-1) self report of grades, 2) attendance, 3) time spent doing homework, 4) academic possible selves and 5) strategies to attain them, and 6) concern about school were assessed. The dimensions were not strongly correlated (see Table 1) and factor analysis was able to recover less than $50 \%$ of the original variance with a reduced set of factors. Therefore, we analyzed the effect of gendered REI on each of these elements of school involvement separately.

\section{School Grades}

Students reported their grades on a 9 -point scale $(0=$ mostly Fs, $1=$ mostly Ds and Fs; $2=$ mostly Ds; $3=$ mostly Cs and Ds; $4=$ mostly Cs; $5=$ mostly Cs and Bs; 


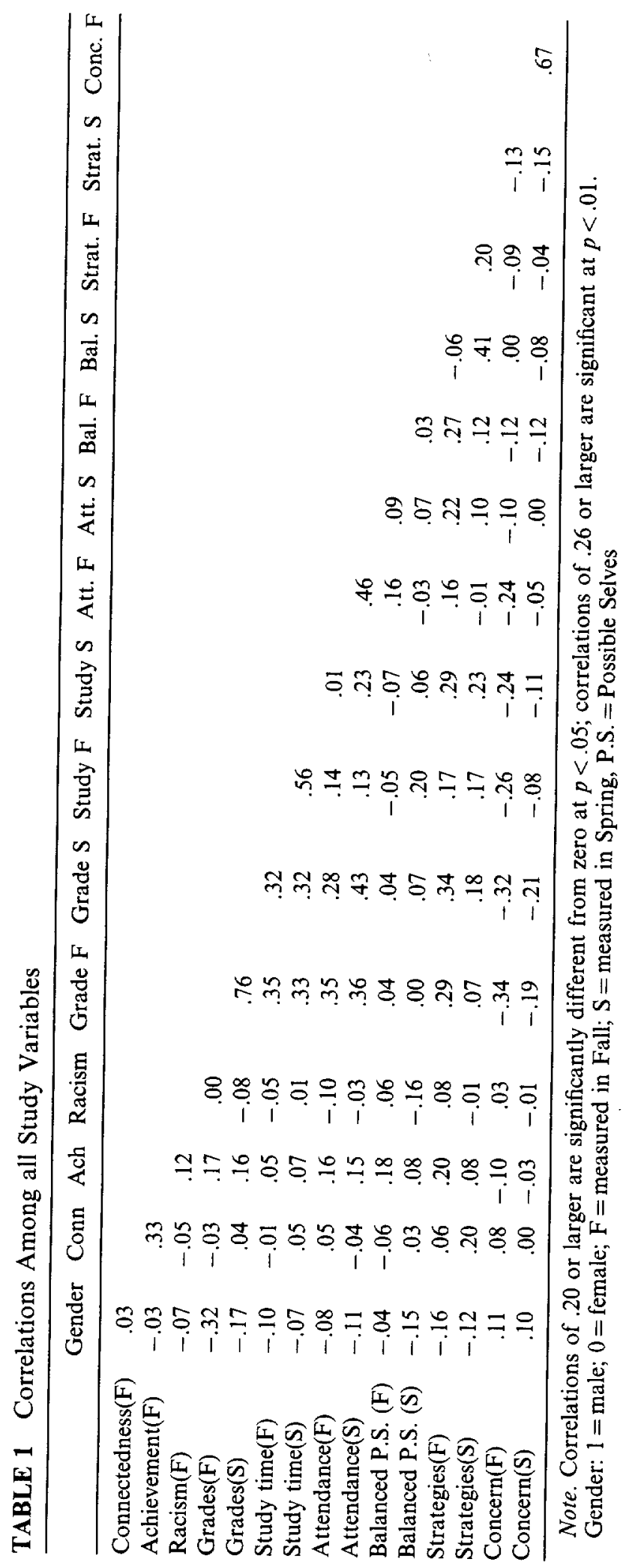


$6=$ mostly Bs; $7=$ mostly As and Bs; $8=$ mostly As); Fall $M=6.14, S D=1.32$; Spring $M=6.07, S D=1.53$.

\section{Homework Time}

Students reported how many hours per week they spent on homework on a 6point scale $(0=$ none, $1=$ less than 1 hour, $2=1-2$ hours, $3=3-5$ hours, $4=5-10$ hours, $5=10$ or more hours), Fall $M=2.15, S D=1.17$; Spring $M=2.28, S D=1.30$.

\section{School Attendance}

Students reported how often they were absent from school on a 5-point scale ( $1=$ more than once a week, $2=$ once a week or so, $3=$ once every few weeks, $4=$ once a month or so, $5=$ less than once a month), Fall $M=4.14, S D=1.26$; Spring $M=3.77, S D=1.29$.

\section{"Balanced" Academic Possible Selves and Strategies}

"Balanced" academic possible selves and strategies were assessed in the Fall and Spring with open-ended probes following a previously developed script (Oyserman \& Markus, 1990; Oyserman \& Saltz, 1993). Students generated four possible selves in response to each of two probes: "Next year, I expect to be..."; "Next year I want to avoid being...," marking possible selves they were currently working on and writing what they were doing to try to attain (or avoid) them. We coded the number of strategies youth generated to attain (or avoid) the school-focused possible selves. Examples of strategies include "doing my homework" and "not talking in class." Each youth specified between 0 to 5 strategies (Fall $M=1.29, S D=1.01$; Spring $M=1.15, S D=1.07$ ).

Next, we read all of the expected and to-be-avoided possible selves and counted the number of times youth described school-focused goals in terms of a positive expectation "balanced" by a related school-focused concern described as a feared self. For example, a positive expectation of "graduating from the eighth grade" coupled with a fear of "getting failing grades" would constitute one instance of balance. Participants had from 0 to 4 instances of balance in the academic domain, Fall $M=0.51, S D=0.66$; Spring $M=0.62, S D=0.78$. Interrater reliability was $90 \%$ on balance and strategies (the first and third authors, blind to the rest of questionnaire responses, coded a third of the interviews separately).

\section{Academic Concern}

Academic concern was measured through a six-item, 5-point Likert scale ( $1=$ never to $5=$ all the time) from Fleming and Courtney (1984). The scale focuses on the extent to which one feels concerned about schoolwork and doing well in school, with higher scores reflecting more concern about academic performance $(\alpha=.80$; Fall $M=2.18, S D=0.92$; Spring $M=2.08, S D=1.07)$.

\section{Analysis Plan}

To study the gendered effects of REI on each component of school involvement, we used hierarchical, moderated regression. This strategy allowed us to examine the interaction of gender and REI, after controlling for the main effects of gender and REI as well as lower-order interactions among the REI components. We used panel data for the analysis, which allowed us to control for prior (Fall) levels of school 
involvement and to use Fall levels of REI to predict Spring levels of school involvement.

This model of analysis has several important strengths, as delineated by Finkel (1995). First, because the regression model contains a measure of prior level of school involvement, regression coefficients can be interpreted as predictive of change in school involvement over the academic year. Second, because the model takes into account prior level of school involvement, unmodeled influences on school involvement are at least partially controlled, allowing a clear focus on the modeled predictors - the interactions of gender and REI. Finally, because the predictors are lagged (measured at a prior point in time), the analysis allows for strong conclusions about the direction of influence between gendered REI and change in school involvement.

Specific analyses utilized a series of hierarchical regression equations in which we predicted Spring (Time 2) level of school involvement from the interaction between gender and the components of REI, entered in the final blocks of the model (blocks 6-8). In the preceding steps we entered prior school involvement (as a control) as well as gender and REI variables. Specifically, at block 1, we entered fall (Time 1) level of school involvement; at block 2, gender; at block 3, main effects for each of the three components of REI; at block 4, two-way interactions between the three components of REI; and at block 5, the three-way interaction among the REI components. Blocks 6 through 8 incorporated Gender in interaction with each REI main effect and interaction: Block 6 contained two-way interactions between Gender and each component of REI; block 7 contained three-way interactions, and block 8 added the four-way interaction between Gender and all three REI components.

To provide a clearer interpretation of coefficients and to reduce collinearity among main and interaction effects, we centered the three components of REI variables before constructing interaction terms. We report only unstandardized coefficients, which for interaction terms are unaffected by centering. To ensure the appropriateness of the analysis, we inspected residuals for heteroscedasticity and the presence of outliers and influential cases. In two instances in which we identified moderate outliers, we conducted analyses with and without the identified cases; differences were trivial and did not affect the significance or interpretation of the results.

Our analyses follow the recommendations of Aiken and West (1991) for structuring, probing, and interpreting higher-order interactions in a multiple regression framework. As they suggest, we used plots and tests of the significance of simple slopes to illuminate the nature of the higher-order interactions (plots are available from the authors). In spite of our modest sample size, power was adequate to detect the hypothesized interactions given the control for prior (Fall) levels of the dependent variable. Power to detect moderating relationships accounting for $5 \%$ of the variance in change ranged from .70 to .90 (as the Fall-to-Spring stability of individual outcomes varied from .20 to .60 ).

\section{Results}

Summaries of hierarchical regression analyses are in Table 2.

\section{Grades}

Overall the equation predicting spring grades was significant, $F(16,76)=9.25$, $p<.001$, adjusted $R^{2}=.60$. There was a significant gender by Connectedness 
¿vels of school

eated by Finkel $f$ prior level of ictive of change lodel takes into n school invol$n$ the modeled : predictors are ing conclusions inge in school

sns in which we action between model (blocks $s$ a control) as d fall (Time 1) cts for each of ween the three nong the REI with each REI ztween Gender Is, and block 8 smponents. ce collinearity inents of REI Instandardized To ensure the sticity and the I we identified entified cases; etation of the

391) for strucple regression nce of simple : are available uate to detect of the depenor $5 \%$ of the ility of indivi-

$6,76)=9.25$, 'onnectedness interaction $(B=.89, p<.01)$ and a significant gender by Embedded Achievement interaction $(B=-.65, p<.03)$ which together significantly improved model fit, $\Delta F(3,80)=3.29, p<.03 ; \Delta R^{2}=.04$. Improved grades were predicted by REI connectedness for boys $(B=.81, p<.01)$, and by REI embedded achievement for girls ( $B=.47, p<.03)$. REI embedded achievement had a dampening effect on grades for boys $(B=-.71, p<.01)$.

\section{Study Time}

The overall equation predicting study time was significant, $F(16,76)=4.10$, $p<.001$, adjusted $R^{2}=.35$; and model fit significantly improved with addition of the gender by components of REI two-way $\left(\Delta F(3,80)=2.67, p<.05, \Delta \mathrm{R}^{2}=.06\right)$, and three-way $\left(\Delta F(3,77)=2.77, p<.05, \Delta R^{2}=.06\right)$ interaction effects. There was a significant 3-way interaction of Connectedness, Embedded Achievement, and Gender $(B=.97, p<.03)$; as well as a significant average effect of Connectedness by Gender $(B=.75, p<.04)$. Inspection of simple slopes at high $(M+1 S D)$ and low $(M-1 S D)$ levels of embedded achievement clarified the nature of the interaction. For boys, connectedness was positively related to study hours (across all levels of embedded achievement, $B=.90, p<.01)$ as predicted. The effects for girls, were more complex, for girls, connectedness dampened study time $(B=-.92, p<.01)$ when girls were high in embedded achievement, although it was unrelated for girls low in embedded achievement $(B=.26, p>.30)$.

\section{Attendance}

The overall equation predicting self-reported attendance was significant, $F(16,75)=3.38, p<.001$, adjusted $R^{2}=.30$; and model fit improved significantly when the 4-way interaction between gender and the components of REI was added to the model, $B=1.45, p<.02 ; \Delta F(1,75)=6.46, p<.02, \Delta R^{2}=.05$. The REI component, Connectedness was positively related to improved self-reported attendance for boys high in both the other components of REI, Embedded Achievement and Awareness of Racism $(B=2.42, p<.01)$. No significant effects were found for girls.

\section{Balanced Academic Possible Selves}

The overall equation predicting balance in academic possible selves was marginally significant, $F(16,83)=1.53, p<.10$, adjusted $R^{2}=.08$; and addition of the 4-way interaction between gender and the components of REI, $B=-.84, p<.02$; $\Delta F(1,83)=5.31, p<.02 ; \Delta R^{2}=.05$, significantly improved model fit. As is the case with study time, high connectedness dampened balance for girls $(B=-1.29, p<.01)$, only when Embedded Achievement was high and Awareness of Racism was low. No effect for boys was found.

\section{Strategies to Attain Academic Possible Selves}

The overall equation predicting strategies to attain academic possible selves was significant, $F(16,84)=1.76, p<.05$, adjusted $R^{2}=.11$; and the addition of the twoway interactions between gender and components of REI made a trend-level contribution to variance explained, $\Delta F(3,88)=2.30, p<.09, \Delta R^{2}=.06$. Specifically there was a two-way interaction between gender and Connectedness, $B=.70, p<.03$, such that connectedness predicted an increase in strategies from Fall to Spring for boys $(B=.70, p<.03)$, but not for girls $(B=-.12, p>.64)$. 


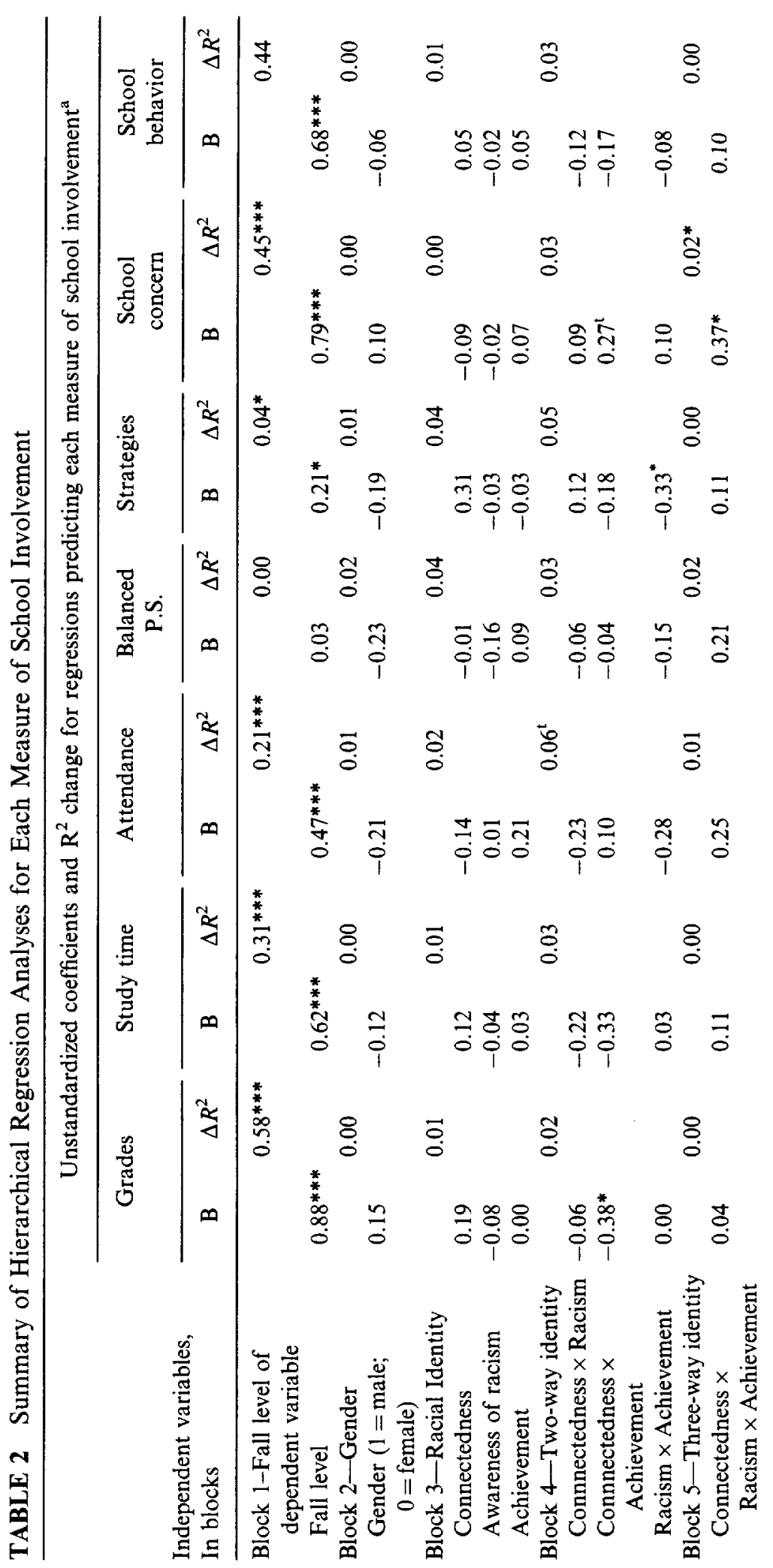




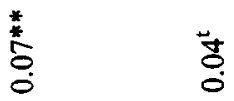

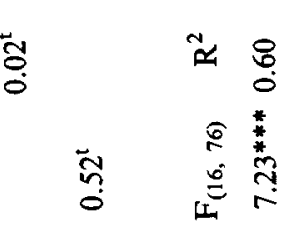

$\because \quad \dot{0}$

8

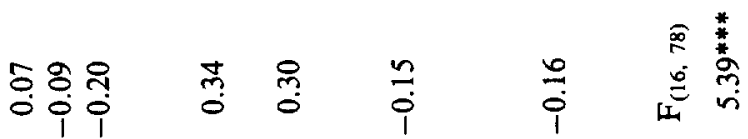

ஜ̊ㅇㅇ

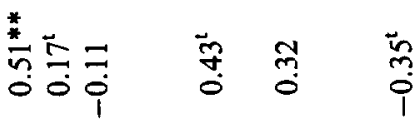

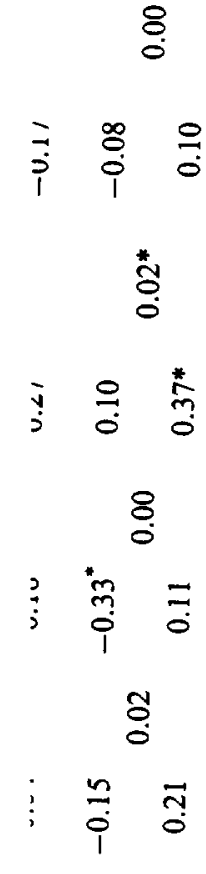

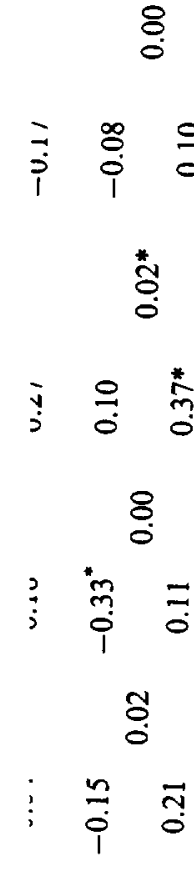

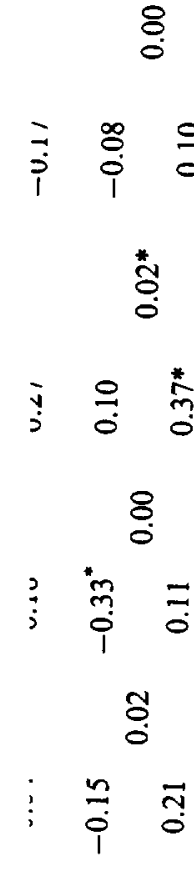

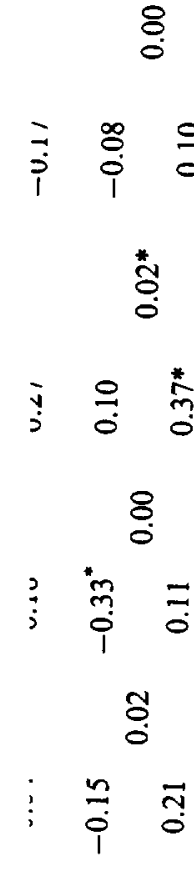

웅

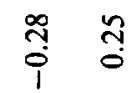

$\stackrel{8}{0}$

$\stackrel{3}{0}=$

8

ஓ̊.

$\stackrel{8}{0}$

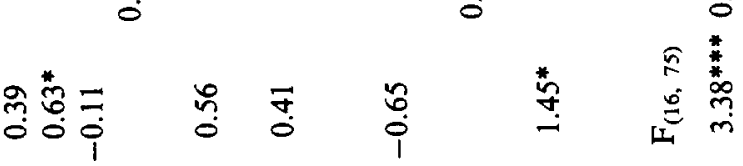

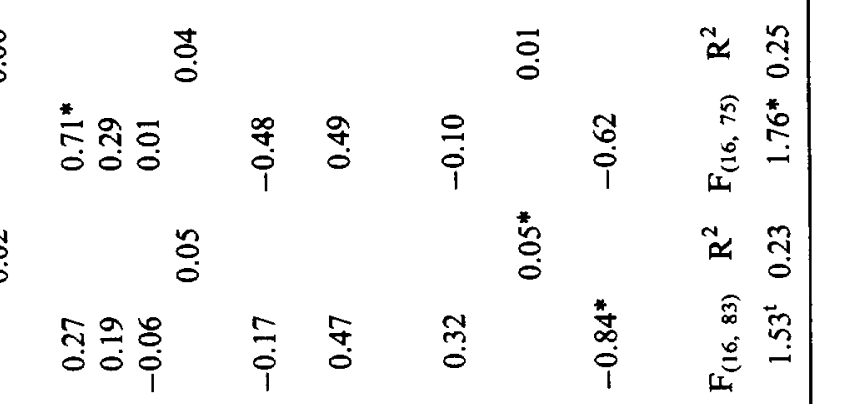

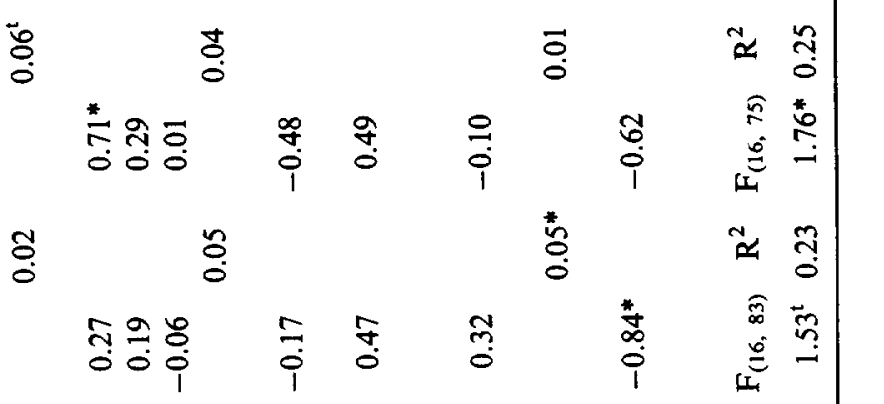

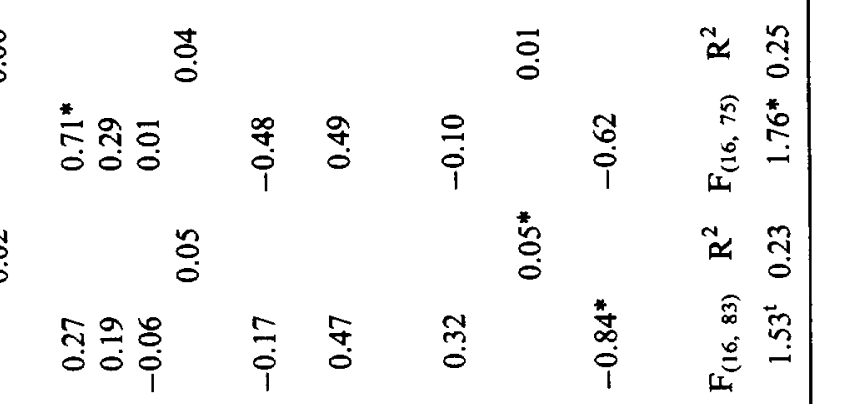

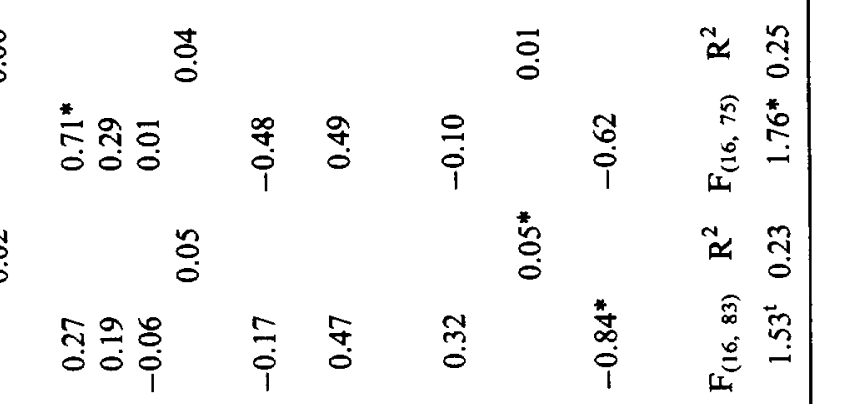

흥

氙

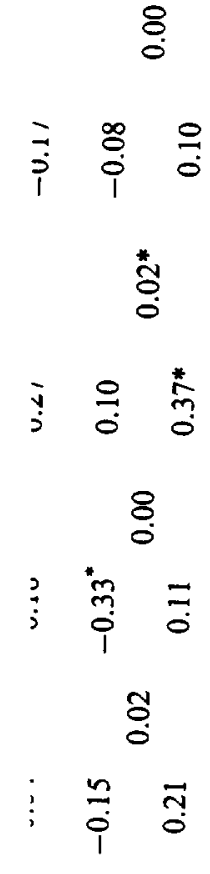

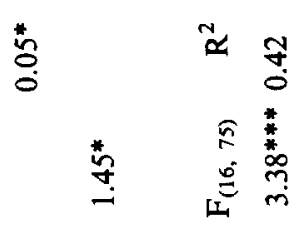

*

8

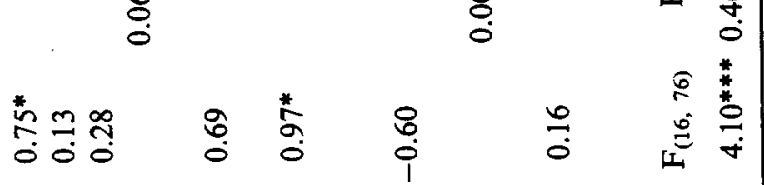

范

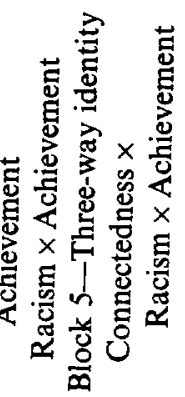




\section{Concern about School}

The overall equation predicting concern about school was significant, $F(16,78)=5.39, p<.001$, adjusted $R^{2}=.43$; and adding the three-way interaction of REI components improved model fit, $B=.37, p<.05, \Delta F(1,85)=4.01, p<.05$, $\Delta R^{2}=.03$ (adding the interaction of Gender and REI components did not significantly improve the model). Connectedness was predictive of change in concern about school only when Awareness of Racism was also high. Calculation of simple slopes showed a trend-level positive relationship between increased concern about school and Connectedness when both Awareness of Racism and Embedded Achievement were high $(B=.50, p<.07)$ and a negative relationship when awareness of Racism was high but Embedded Achievement was low $(B=-.42, p<.08)$.

\section{Discussion}

In the current research, we asked if youths do indeed describe REI in terms of Connectedness, Awareness of Racism, and Embedded Achievement and found evidence that these REI elements can be discerned with a variety of methods. We then explored the implications of three components of gendered REI for school involvement. We proposed that gendered REI would promote school involvement when Gender and REI-based expectations melded to form a social identity that contained both relational and agentic aspects. We postulated that the influence of REI would be gendered because the agentic and relational aspects of REI would interact with and offset the agentic and relational foci of gender socialization. In terms of self-concept, girls were assumed already likely to focus on interpersonal and interconnected aspects of self-concept, while boys were assumed to be more likely to focus on the independent and agentic aspects of the self-concept (e.g. Bakan, 1966; Cross \& Madson, 1997; Markus \& Oyserman, 1989). In this way, REI would be "gendered" because it would be incorporated into differing structures of self-concept for boys and girls.

Following this model, we speculated that the connectedness element of REI provides a new way to see the self for boys and is redundant for girls, while the achievement element provides a new way for girls to see themselves and is redundant for boys. Since both agentic and interrelated aspects of the self have important consequences, having both agentic and interrelated identity elements is likely to be helpful (e.g., McAdoo, 1991). Perhaps because the independence and autonomy messages provided to males might otherwise inadvertently increase risk of rootlessness and anomie, the positive connectedness aspects of REI did in fact seem particularly helpful for males in our sample. Conversely, for females, connectedness was not helpful-perhaps because relational messages already abound for girls; it is more a focus on achievement that is helpful for girls. We found consistent support for the hypothesized positive effect of connectedness for boys in increasing grades, study time, attendance, strategies to attain academic possible selves, and concern about school. Evidence for the positive effect of embedded achievement for girls came from the improved grades of girls high in this REI component. In addition, with regard to connectedness, this REI component had a detrimental effect for girls-suggesting that a double dose of relationality may be harmful for school involvement especially as it relates to study time and having balanced academic possible selves.

To rule out the possibility that our findings of gendered influence of REI on school involvement are simply due to a gender main effect on either content of REI 
as significant, $\checkmark$ interaction of $=4.01, p<.05$, $s$ did not signge in concern ition of simple concern about ad Embedded hen awareness $-.42, p<.08$ ).

in in terms of nt and found methods. We EI for school 1 involvement I identity that te influence of of REI would cialization. In rpersonal and more likely to Bakan, 1966; ¿EI would be ,f self-concept

\section{ment of REI} rls, while the $I$ is redundant ve important is likely to be id autonomy risk of rootin fact seem onnectedness for girls; it is stent support asing grades, and concern lent for girls In addition, tal effect for ll for school ed academic

e of REI on ntent of REI or extent of school involvement we examined the possibility of a gender main effect on REI and school involvement using a series of analyses of variance. Only a single gender main effect was found (girls report significantly higher Fall grades $(\mathrm{F}[1,91]=6.96, p<.01)$. Because we controlled for this effect by entering gender and Fall grades into the analyses of the effects of gendered REI, we are confident that our results are due to the gendered impact of REI on school involvement. To explore the robustness of the negative effect of REI connectedness for girls we also re-analyzed the data combining the three school behavior scales (attendance, grades, and study time), first standardizing each to bring their variances into the same metric, and then averaged to form a self-report school behavior scale. This 3 -item scale had internal consistency of .54 in the Fall and .59 in the Spring, when predicting school behaviors controlling for fall report of these behaviors, $F(16,76)=7.23, p<.001$, adjusted $R^{2}=.52$, we found a significant gender by REI connectedness interaction, $(B=.51$, $p<.01)$, which showed a positive effect of REI connectedness for boys $(B=.26$, $p<.06)$ and a negative effect of connectedness for girls $(B=-.26, p<.03)$.

An emerging experimental literature suggests that making social class, gender, or race salient undermines academic performance (e.g. Croizet \& Claire, 1998; Osborne, 1995; Steele \& Aronson, 1995), for those negatively stereotyped through their membership in these categories. This highlights the importance of our finding that elements of REI can be promotive of positive academic focus among low-income minority youth. When race is made salient, if what comes to mind is positive REI connectedness, boys' performance should not be undermined, though it appears that girls' performance would be. Conversely, if what comes to mind is positive REI embedded achievement, this may be helpful for girls' performance. The current study is a first step in making sense of the content and consequences of gendered REI in adolescence.

Our focus was on the role of gendered REI in conditions of economic stress among youth living in racially homogeneous inner-city contexts. The elements of gendered REI we focused on were connectedness, awareness of racism and embedded achievement. REI may well take on different content and functions in contexts that are racially heterogeneous and economically less stressed. Greater access to the economic resources may improve academic achievement, but may have detrimental effects on minority youth attempting to connect their REI with academics. Similarly, racially heterogeneous contexts may highlight subtle and not so subtle racism in the form of exclusion or "claiming" of academic involvement as part of ingroup identity by members of one racial-ethnic group, leaving others to self define as not schoolfocused. The extent to which these contexts make race more or less salient and the degree to which performance in school is promoted or hindered by thinking about one's REI in these contexts remains to be explored. We have focused on youths and on those elements of REI relevant to academic achievement. A more general model of REI would focus on connectedness to ingroup, awareness of racism, and sense of connection to larger society and its goals and values.

\section{References}

Aguirre, A., \& Turner, J. (1998) American ethnicity: The dynamics and consequences of discrimination (2nd ed.). Boston: McGraw-Hill.

Aiken, L. S., \& West, S. G. (1991). Multiple regression: Testing and interpreting interactions. Newbury Park, CA: Sage 
Allen, W. (1992). The color of success: African-American college student outcomes at predominantly white and historically black public colleges and universities. Harvard Educational Review, 62, 2644.

Allen, R., \& Dawson, M., \& Brown, R. (1989). A schema-based approach to modeling an African-American racial belief system. American Political Science Review, 83, 421-441.

Azibo, D. A. Y. (1991). An empirical test of the fundamental postulates of an African personality metatheory. The Western Journal of Black Studies, 15, 183-195.

Bakan, D. (1966). The duality of human existence. Chicago: Rand McNally.

Banaji, M. R., \& Prentice, D. A. (1994). The self in social contexts. Annual Review of $P_{s y-}$ chology, 45, 297-332.

Bowman, P. (1992). Coping with provider role strain: Adaptive cultural resources among black husband-fathers. In A. Burlew, W. Banks, H. McAdoo, \& D. Azibo (Eds.), African American psychology: Theory, research, and practice (pp. 135-154). Newbury Park, CA: Sage.

Bowser, B., \& Perkins, H. (1991). Success against the odds: Young black men tell what it takes. In B. Bowser (Ed.), Black male adolescents: Parenting and education in community context (pp. 183-200). New York: University Press.

Cantor, N., \& Zirkel, S. (1990). Personality, cognition, and purposive behavior. In L. A. Pervin (Ed.), Handbook of personality theory and research (pp. 135-164). New York:
Guilford.

Cose, E. (1993). The rage of a privileged class. New York: Harper Collins.

Crocker, J., Luhtanen, R., Blaine, B., \& Broadnax, S. (1994). Collective self-esteem and psychological well-being among white, black, and Asian college students. Personality and Social Psychology Bulletin, 20, 503-513.

Crocker, J., \& Major, B. (1989). Social stigma and self-esteem: The self-protective properties of stigma. Psychological Review, 96, 608-630.

Croizet J., \& Claire, T. (1998). Extending the concept of stereotype threat to social class: The intellectual underperformance of students from low socioeconomic backgrounds. Personality and Social Psychology Bulletin, 24, 588-594. Cross, W. E. (1991). Shades of black: Diversity in African-American identity. Philadelphia:
Temple University Press.

Cross, S. E., \& Madson, L. (1997). Models of the self: Self-construals and gender. Psychological Bulletin, 122, 5-37.

Daniels, M., Wodarski, J. S., \& Davis, K. (1987). Education for community mental health practice with Blacks. Journal of Social Work Education, 1, 40-47.

Dyson, M. E. (1993). Reflecting black African-American cultural criticism. Minneapolis, MN: University of Minnesota Press.

Elliott, G. R., \& Feldman, S. S. (1990). Capturing the adolescent experience. In S. S. Feldman \& G. R. Elliott (Eds.), At the threshold: The developing adolescent. Cambridge, MA: Harvard University Press.

Essed, P. (1990). Everyday racism. Claremont, CA: Hunter House Inc.

Finkel, S. E. (1995). Causal analysis with panel data. Sage University Paper series on Quantitative Applications in the Social Sciences, 07-105. Thousand Oaks, CA: Sage.

Fleming, J., \& Courtney, B. (1984). The dimensionality of self-esteem II: Hierarchial facet model for revised measurement scale. Journal of Personality and Social Psychology, 46, 404-421.

Ford, D. (1992). Self-perceptions of underachievement and support for the achievement ideology among early adolescent African-Americans. Journal of Early Adolescence, 12(3),

Fordham, S. (1988). Racelessness as a strategy in Black students' school success: Pragmatic strategy or pyrrhic victory? Harvard Educational Review, 58(1), 54-84.

Fordham, S., \& Ogbu, J. U. (1986). Black students school success: Coping with the "burden of acting white." The Urban Review, 18, 176-206. 
it outcomes at preities. Harvard Edu-

ch to modeling an view, 83, 421-441. ttes of an African 3-195.

y. ral Review of Psyresources among ibo (Eds.), African swbury Park, CA:

men tell what it tion in community

havior. In L. A. 164). New York:

self-esteem and Personality and ective properties social class: The skgrounds. Per-

y. Philadelphia:

sender. Psycho-

' mental health

Ineapolis, MN:

S. S. Feldman mbridge, MA:

rries on QuanSage. zrarchial facet sychology, 46,

achievement sscence, 12(3),

ss: Pragmatic le "burden of
Gardner, W., Gabriel, S., \& Lee, A. (1999). "I" value freedom but "we" value relationships: Self-construal priming mirrors cultural differences in judgment. Psychological Science, 10, 321-326.

Harter, S., \& Marold, D. B. (1991). A model of the determinants and mediation role of selfworth: Implications for adolescent depression and suicidal ideation. In J. Strauss \& G. R. Goethals (Eds.), The self: Interdisciplinary approaches (pp. 66-92). New York: Springer-Verlag.

Jackson, J. S. (Ed.). (1991). Life in black America. Newbury Park, CA: Sage.

Jencks, C. (1991). Is the American underclass growing? In C. Jenks \& P. E. Peterson (Eds.), The urban underclass. Washington, DC: Brookings.

Kashima, Y., Yamaguchi, S., Kim, U., Choi, S., Gefand, M., \& Yuki, M. (1995). Culture, gender and self: A perspective from individualism-collectivism research. Journal of Personality and Social Psychology, 69, 925-937.

Kihlstrom, J. F., \& Klein, S. (1994). The self as a knowledge structure. In R. Wyer, Jr., \& Srull, T. (Eds.), Handbook of social cognition (2nd ed., Vol. 1). Hillsdale, NJ: Erlbaum.

Kirschenman, J., \& Neckerman, K. M. (1991). "We'd love to hire them, but ...": The meaning of race for employers. In C. Jencks, \& P. E. Peterson (Eds.), The urban underclass (pp. 203-232). Washington, DC: Brookings.

Kowaleski-Jones, L., \& Duncan, G. (1999). The structure of achievement and behavior across middle childhood. Child Development, 70, 930-943.

Leffert, N., \& Petersen, A. C. (1995). Patterns of development during adolescence. In M. Rutter \& D. J. Smith (Eds.), Psychosocial disorders in young people: Time trends and their causes (pp. 67-103). New York: Wiley.

Lewin, K. (1948). Resolving social conflicts: Selected papers on group dynamics (1935-1946) (1st ed.). New York: Harper.

Macrae, C. N., Stangor, C., \& Milne, A. B. (1994). Activating social stereotypes: A functional analysis. Journal of Experimental Social Psychology, 30(4), 370-389.

Madon, S., Jussim, L., \& Keiper, S. (1998). The accuracy and power of sex, social class, and ethnic stereotypes: A naturalistic study in person perception. The Journal of Personality and Social Psychology, 24, 1304-1318.

Markus, H., \& Oyserman, D. (1989). Gender and thought: The role of the self-concept. In M. Crawford \& M. Gentry (Eds.), Gender and thought: Psychological perspectives. New York: Springer-Verlag.

Massey, G. (1991). The flip side of teen mothers: A look at teen fathers. In B. Bowser (Ed.), Black male adolescents: Parenting and education in community context (pp. 117-128). New York: University Press.

McAdoo, J. (1991). The roles of black fathers in the socialization of black children. In H. McAdoo (Ed.), Black families (pp. 257-269). Newbury Park; CA: Sage.

McNair-Knox, F. (1991). Tapping into teen talk: Parenting strategies for bridging the intergenerational communication gap. In B. Bowser (Ed.), Black male adolescents: Parenting and education in community context (pp. 235-258). New York: University Press.

Miller, L. S. (1995). An American imperative: Accelerating minority educational advancement. London: Yale University Press.

Ogbu, J. U. (1991). Minority coping responses and school experience. The Journal of Psychohistory, 18, 433-456.

Osborne, J. (1995). Academics, self-esteem, and race: A look at the underlying assumptions of the disidentification hypothesis. Personality \& Social Psychology Bulletin, 21, 449-455.

Oyserman, D., Gant, L., \& Ager, J. (1995). A socially contextualized model of African American identity: School persistence and possible selves. Journal of Personality and Social Psychology, 69, 1216-1232.

Oyserman, D., \& Harrison, K. (1998). Implications of cultural context: African American identity and possible selves. In J. Swim \& C. Stanger (Eds.), Prejudice: The target's perspective (pp. 281-300). San Diego, CA: Academic Press. 
Oyserman, D., \& Markus, H. R. (1990). Possible selves in balance: Implications for delin quency. Journal of Social Issues, 46, 141-157.

Oyserman, D., \& Markus, H. (1993). The socio-cultural self. In J. Suls (Ed.), Psychological perspectives on the self: Vol 4 (pp. 187-220). Hillsdale, NJ: Erlbaum.

Oyserman, D., \& Packer, M. (1996). Social cognition and self concept: A socially contextualized model of identity. In J. Nye \& A. Brower (Eds.), What's so social about social

Oyserman, D., \& Saltz, E (1993). Competence, CA: Sage. selves. Journal of Personality and

Parham, T., \& Helms, J. (1985). Relation affective states of black students.

Paschall, M., \& Hubbard, M. (1998). Journal of Counseling Psychology, 32, 431-440. American male adolescents' self Effects of neighborhood and family stressors on African Consulting and Clinical Psychology, 66, 825-831.

Phinney, J S. (1990). Ethnic identity , 66, 825-831.

logical Bulletin, 108(3), 499-514.

Phinney, J. S. (1996). When we talk about American ethnic groups, what do we mean? American Psychologist, 51, 918-927. Quintana, S. M. (1998). Children's developmental understanding of ethnicity and race.
Applied \& Preventive Psychology, 7, 27-45.

Rudman, L. A. (1998). Self-promotion as a risk factor for women: The costs and benefits of counterstereotypical impression management. Journal of Personality \& Social Psychology,
$74,629-645$.

Shorter-Gooden, K., \& Washington, N. (1996). Young, black, and female: the challenge of weaving an identity. Journal of Adolescence, 19, 465-475.

Stangor, C., \& Lange, J. E. (1994). Mental representations of social-groups: Advances in 26,357-416.

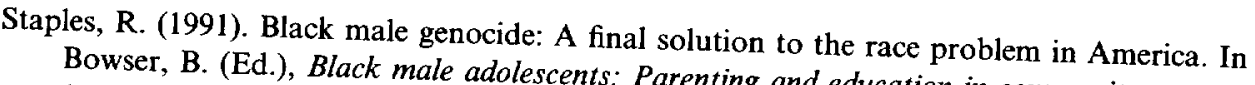
Bowser, B. (Ed.), Black male adolescents: Parenting and education in community context
(pp. 39-57). New York: University Press.

Steele, C. (1997). A burden of suspicion: How ste performance of women and Afican: How stereotypes shape the intellectual identities and

Steele, C., \& Aronson, J. (1995). Stereotype threat and the Psychologist, 52, 613-629. African Americans. Journal of Personality and and the intellectual test performance of

Stevens, J. W. (1997). African American Social Psychology, 69, 797-811. dimensional perspective. Child Welfare, $76,145-172$.

Stevenson, H. (1995) Relationship of are, 76, 145-172. identity. Journal of Black Psychology,21,49-70.

Wilson, W. (1993) The sociology of the public agenda. Newbury Park, CA: Sage. 